\title{
Phosphodiesterase-5 inhibition and cardioprotection: potential role of hydrogen sulfide
}

\author{
Rakesh C Kukreja*, Vinh Q Chau, Nicholas N Hoke, Antonio Abbate, \\ Amit Varma, Ramzi A Ockaili, Stefano Toldo and Fadi N Salloum
}

\author{
Address: Division of Cardiology, Department of Internal Medicine, Virginia Commonwealth University, Richmond, VA 23298-0204, USA \\ Email: Rakesh C Kukreja* - rakesh@vcu.edu \\ * Corresponding author
}

\author{
from 4th International Conference of cGMP Generators, Effectors and Therapeutic Implications \\ Regensburg, Germany. 19-21 June 2009 \\ Published: II August 2009 \\ BMC Pharmacology 2009, 9(SuppI I):S24 doi:I0.II86/I47I-22I 0-9-SI-S24
}

This abstract is available from: http://www.biomedcentral.com/I47I-22I0/9/SI/S24

(c) 2009 Kukreja et al; licensee BioMed Central Ltd.

\section{Background}

Our laboratory has shown that phosphodiesterase-5 (PDE-5) inhibitors including sildenafil, vardenafil and tadalafil induce powerful protection against myocardial ischemia-reperfusion injury. We have shown that sildenafil protects through activation PKC, expression of eNOS/ iNOS, protein kinase G (PKG) and opening of mitochondrial KATP (mitoKATP) channels [1]. Hydrogen sulfide (H2S) is a gaseous molecule that is produced enzymatically and exerts physiological actions in the cardiovascular system. Similar to PKG, H2S has been shown to protect the heart via opening of mitoKATP channel [2]. In the current study, we hypothesized that tadalafil, the long acting inhibitor of PDE-5 mediates cardioprotection through H2S signaling in a PKG-dependent fashion.

\section{Methods and results}

After baseline transthoracic echocardiography (TTE), adult ICR mice were injected i.p. with vehicle $(10 \%$ DMSO) or tadalafil (1 mg/kg) with or without KT5823 (KT, PKG blocker, $1 \mathrm{mg} / \mathrm{kg}$ ) or dl-propargylglycine [PAG, Cystathionine- $\gamma$-lyase (CSE, H2S-producing enzyme) blocker; $50 \mathrm{mg} / \mathrm{kg}] 1 \mathrm{~h}$ prior to coronary artery ligation for $30 \mathrm{~min}$ and reperfusion for $24 \mathrm{~h}$, whereas C57BL-wild type and CSE-knockout mice were treated with either vehicle or tadalafil. After reperfusion, TTE was performed and hearts were collected for infarct size (IS) measurement using TTC staining. Survival was increased with tadalafil (95\%) compared with control (65\%, P < 0.05).
Infarct size was reduced with tadalafil $(13.2 \pm 1.7 \%)$ compared to vehicle $(40.6 \pm 2.5 \% ; \mathrm{P}<0.05)$. KT and PAG abolished tadalafil-induced protection (IS: $39.2 \pm 1 \%$ and $51.2 \pm 2.4 \%$, respectively) similar to genetic deletion of CSE $(47.2 \pm 5.1 \%)$. Moreover, tadalafil preserved fractional shortening (FS: $31 \pm 1.5 \%$ ) compared to control (FS: $22 \pm 4.8 \%, \mathrm{P}<0.05$ ). Baseline FS was $44 \pm 1.7 \%$. KT and PAG abrogated the preservation of LV function with tadalafil by decline in FS to $17 \pm 1 \%$ and $23 \pm 3 \%$, respectively. Compared to vehicle, myocardial $\mathrm{H} 2 \mathrm{~S}$ production was significantly increased with tadalafil and was abolished with KT.

\section{Conclusion}

PKG activation with tadalafil limits myocardial infarction and preserves LV function through H2S signaling.

\section{References}

I. Kukreja RC, Salloum F, Das A, Ockaili R, Yin C, Bremer YA, Fisher PW, Wittkamp M, Hawkins J, Chou E, Kukreja AK, Wang X, Marwaha VR, Xi L: Pharmacological preconditioning with sildenafil: Basic mechanisms and clinical implications. Vascul Pharmacol 2005, 42:219-32.

2. Elrod JW, Calvert JW, Morrison J, Doeller JE, Kraus DW, Tao L, Jiao X, Scalia R, Kiss L, Szabo C, Kimura H, Chow CW, Lefer D]: Hydrogen sulfide attenuates myocardial ischemia-reperfusion injury by preservation of mitochondrial function. Proc Natl Acad Sci USA 2007, 104:15560-5. 